\title{
Glucocorticoid resistant asthma: T-lymphocyte steroid metabolism and sensitivity to glucocorticoids and immunosuppressive agents
}

\author{
C.J. Corrigan*, J.K. Bungre**, B. Assoufi**, A.E. Cooper+, H. Seddon+, A.B. Kay**
}

Glucocorticoid resistant asthma: T-lymphocyte steroid metabolism and sensitivity to glucocorticoids and immunosuppressive agents. C.J. Corrigan, J.K. Bungre, B. Assoufi, A.E. Cooper, H. Seddon, A.B. Kay. (CERS Journals Ltd 1996.

ABSTRACT: We have previously shown that T-lymphocytes from clinically glucocorticoid (GC) resistant asthmatics are more refractory to dexamethasone suppression in vitro than those of GC sensitive asthmatics. We wished to extend these observations to compare three GCs used topically for asthma therapy (budesonide, beclomethasone dipropionate and fluticasone $17 \alpha$-propionate) and three immunosuppressive drugs (cyclosporin A, FK506 (tacrolimus) and mycophenolate mofetil) with dexamethasone for their antiproliferative effects on T-lymphocytes from GC sensitive and resistant asthmatics, and also to compare the rates of steroid metabolism by T-lymphocytes from these patients.

Antiproliferative activity of the drugs was measured on peripheral blood T-lymphocytes activated with phytohaemagglutinin (PHA) and anti-CD3 antibody in vitro. The rates of total steroid metabolism and $20 \alpha$-hydroxylation by T-cell homogenates were measured using radiolabelled progesterone as an established probe substrate.

Over a wide concentration range, T-lymphocytes from GC resistant asthmatics were significantly less inhibited by all four GCs as compared with cells from GC sensitive asthmatics. The median inhibitory concentrations (IC50) for inhibition of T-lymphocytes from the GC resistant asthmatics exceeded those likely to be achieved therapeutically by systemic administration (although higher concentrations might in theory be achieved locally in the bronchial mucosa by inhaled administration). In contrast, all three immunosuppressive drugs at putative therapeutic concentrations inhibited T-lymphocytes both from GC sensitive and resistant asthmatics with equivalent potency. The rates of total metabolism and $20 \alpha$-hydroxylation of steroid by homogenates of T-lymphocytes from GC sensitive and resistant asthmatics were equivalent.

Thus, relative GC resistance in T-lymphocytes from GC resistant as compared with sensitive asthmatics is: 1) manifest with GC molecules of variable molecular structure; 2) not accompanied by elevated intracellular metabolism of steroids; and 3) overcome by immunosuppressive drugs which inhibit T-lymphocytes by non-GC-mediated mechanisms. We conclude that current anti-asthma glucocorticoids at therapeutic concentrations are unlikely to be of benefit for the therapy of glucocorticoid resistant asthma, and that other immunosuppressive drugs may have potential as therapeutic agents in these patients. Eur Respir J., 1996, 9, 2077-2086.
*Dept of Medicine, Charing Cross \& Westminster Medical School, London, UK **Al lergy \& Clinical Immunology, National Heart \& Lung Institute, London, UK. ${ }^{+}$Astra Charnwood, Loughborough, Leicestershire, UK

Correspondence: C.J. Corrigan

Dept of Medicine

Charing Cross \& Westminster Medical School

Fulham Palace Road

London W6 8RF

UK

\section{Keywords: Asthma}

glucocorticoid

immunosuppressants

metabolism

resistance

T-lymphocytes

Received: January 151996

Accepted after revision July 91996

Supported by a Clinician Scientist Fellowship awarded to CJC by the Medical Research Council (UK), and partly by Glaxo UK, Roche Products Ltd, Fujisawa Pharmaceutical Co. Ltd and Sandoz Pharmaceuticals.
Over the past few years, studies have accumulated in support of a role for T-lymphocytes in the pathogenesis of asthma. Elevated numbers of activated T-lymphocytes were identified in the bronchial mucosa, bronchoalveolar lavage (BAL) fluid, and peripheral blood of asthmatics as compared with controls [1-5]. Peripheral blood T-lymphocyte activation was reduced after glucocorticoid (GC) therapy of severe asthmatics to a degree which correlated with the extent of clinical improvement [5]. Cells both in the bronchial mucosa and BAL fluid of patients with asthma have been shown to synthesize messenger ribonucleic acid (mRNA) encoding cytokines, which are relevant to eosinophil accumulation and activation, a cardinal feature of asthma [6, 7]. In a controlled trial, GC but not placebo therapy of asthmatics resulted in clinical improvement and a reduction in the percentages of BAL cells expressing these cytokines [8].

These observations indicate that GCs exert their antiasthma activity, at least partly, by inhibition of activated T-lymphocytes. There exists, however, a subset of asthmatics who respond poorly or not at all to GC therapy $[9,10]$. Although this phenomenon is relatively uncommon, an understanding of the mechanisms involved may provide important information regarding the antiasthma effects of GCs and why they fail in some 
patients. Furthermore, GC resistance poses a therapeutic problem, since no equally effective anti-inflammatory therapy is currently available.

We and others have shown that GC resistance in asthma is not attributable to altered GC pharmacokinetics $[10,11]$. The clinical sensitivity of asthmatics to GC therapy can be correlated with the sensitivity of their peripheral blood T-lymphocytes to GC inhibition of proliferation and cytokine synthesis in vitro $[10,12,13]$. Thus, peripheral blood T-lymphocytes from GC resistant asthmatics show a defective response to GCs in vitro.

Glucocorticoids act by binding to and activating a specific cytosolic receptor, which translocates to the nucleus and binds as a dimer to specific sites on cellular deoxyribonucleic acid (DNA) (GC response elements) situated upstream of the promoter regions of GC-responsive genes, modulating expression of these genes [14]. In T-lymphocytes, GCs inhibit transcription of cytokines, including the growth factor interleukin-2 (IL2). Although we [10], and others [15], have reported a reduced receptor binding affinity of GCs in T-lymphocytes from GC resistant asthmatics, which may be cytokine-induced [16], it seems unlikely that these small differences in affinity could account entirely for the profound reductions in GC responsiveness observed in peripheral blood T-lymphocytes from resistant patients [10]. Furthermore, chemical mutational analysis shows no evidence for structural abnormalities of the GC receptor gene in sensitive and resistant asthmatics [17]. All of this evidence suggests that GC resistance may result either from abnormal metabolism of GC within the resistant T-lymphocytes, or from a reduced capacity of the activated GC receptor to bind to response elements within these cells. Some evidence in support of the latter possibility has recently been reported [18]. Investigation of the former possibility is the subject of the present study.

To investigate this possibility, we first compared several GCs used for asthma therapy (budesonide, beclomethasone dipropionate and fluticasone $17 \alpha$-propionate) with dexamethasone for their inhibitory effects on the proliferation of peripheral blood T-lymphocytes from GC sensitive and resistant asthmatics activated by phytohaemagglutinin (PHA) and anti-CD3 antibodies. We hypothesized that, if GC resistance arises from heightened metabolism of GCs in T-lymphocytes, GCs of different molecular structures might be metabolized at different rates in "resistant" T-lymphocytes, resulting in different degrees of inhibition of these cells as compared with "sensitive" T-lymphocytes. Secondly, we compared the activity of the enzyme $20 \alpha$-hydroxysteroid dehydrogenase (20 $\alpha$-HSDH) in peripheral blood T-lymphocytes from GC sensitive and resistant asthmatics. Previous evidence $[19,20]$ has suggested that this enzyme was rate-limiting for GC metabolism in T- lymphocytes, and, furthermore, that its activity was higher in T-lymphocytes relatively resistant to GC. We hypothesized that this enzyme shows greater activity in T-lymphocytes from GC resistant as compared with sensitive asthmatics. Finally, we compared the inhibitory effects of the immunosuppressive drugs, FK506 (tacrolimus) and mycophenolate mofetil, on T-lymphocytes from GC sensitive and resistant asthmatics. We hypothesized that, as we have previously reported in the case of cyclosporin A (CsA) [21, 22], these non-GC anti-T-cell drugs inhibit T-lymphocytes from GC sensitive and resistant asthmatics with equivalent potency.

\section{Methods}

\section{Patient selection}

Patients with moderate to severe asthma (forced expiratory volume in one second $(\mathrm{FEV} 1) \leq 70 \%$ predicted despite high-dose inhaled GC therapy) were characterized clinically as sensitive or resistant to oral GC therapy according to their FEV1 response to orally administered prednisolone $[10,22]$. After a run-in period of 7 days, in which it was established that all patients had stable asthma (defined as $<5 \%$ variability in morning prebronchodilator peak expiratory flow rate (PEFR) measurements), baseline FEV1 (prebronchodilator) was measured in all patients with a dry bellows spirometer (Vitalograph, Buckingham, UK). The patients were then prescribed oral prednisolone, $20 \mathrm{mg}$ daily, and FEV1 (prebronchodilator) was remeasured after 7 days at the same time of day. Inhaled GC therapy was continued unchanged. If the FEV1 had not improved by $>30 \%$ of baseline, patients were prescribed prednisolone, $40 \mathrm{mg}$ daily, for an additional 7 days. Consumption of tablets was verified by careful tablet counting by the attending physician rather than by measurement of plasma prednisolone concentrations as in previous studies [10], since we had clearly shown in these studies that GC resistance is not attributable to poor compliance, and all the subjects in the present study were highly motivated to comply with the protocol. Patients who showed an increase in prebronchodilator FEV1 of $\geq 15 \%$ from baseline after this 14 day course of oral GC therapy were classified as sensitive, the remainder were classified as resistant.

Seven sensitive and nine resistant patients were recruited for the present study (table 1). Informed consent was obtained from all patients prior to participation in the study, which was approved by the Ethics Committee of the Royal Brompton Hospital. All patients remained afebrile throughout the study, had normal chest radiographic films and did not suffer from any chronic disease other than asthma. They were taking no medication other than that specified in table 1 . In selecting patients, strict criteria were invoked for the diagnosis of asthma and to exclude patients with irreversible airways obstruction. Thus, all patients were required to demonstrate reversibility of $\geq 15 \%$ in their peak expiratory flow rate or FEV1 after administration of inhaled $\beta_{2}$-agonist (nebulized salbutamol $5 \mathrm{mg}$ ). Smokers were excluded.

\section{Cell culture}

Stock solutions were prepared as follows. Appropriate dilutions were made up in RPMI-1640 (Gibco, Paisley, UK) supplemented with L-glutamine, $2 \mathrm{mmol} \cdot \mathrm{L}^{-1}$ (Gibco), and $5 \% \mathrm{v} / \mathrm{v}$ heat-inactivated foetal bovine serum (Gibco). 
Table 1. - Clinical characteristics of glucocorticoid sensitive and resistant asthmatics

\begin{tabular}{|c|c|c|c|c|c|}
\hline $\begin{array}{l}\text { Age } \\
\text { yrs }\end{array}$ & Sex & $\begin{array}{l}\text { Therapy* } \\
\mu \mathrm{g} \cdot \text { day }^{-1}\end{array}$ & $\begin{array}{l}\text { FEV1 at } \\
\text { baseline } \\
\% \text { pred }\end{array}$ & $\begin{array}{c}\Delta \mathrm{FEV}_{1} \text { after } \\
\beta_{2} \text {-agonist } \\
\%\end{array}$ & $\begin{array}{c}\triangle \mathrm{FEV} 1 \text { after } \\
\text { prednisolone } \\
\%\end{array}$ \\
\hline \multicolumn{6}{|c|}{ Sensitive } \\
\hline 45 & $\mathrm{~F}$ & BDP 2000 & 38 & 29 & 42 \\
\hline 22 & M & BDP 800 & 67 & 43 & 30 \\
\hline 70 & $\mathrm{~F}$ & BDP 1500 & 69 & 53 & 47 \\
\hline 34 & $\mathrm{~F}$ & BDP 1500 & 62 & 34 & 31 \\
\hline 63 & F & BDP 2000 & 29 & 22 & 61 \\
\hline 49 & $\mathrm{~F}$ & BDP 2000 & 48 & 22 & 32 \\
\hline 49 & M & BDP 2000 & 64 & 33 & 38 \\
\hline \multicolumn{6}{|c|}{ Resistant } \\
\hline \multirow[t]{3}{*}{61} & $\mathrm{~F}$ & BDP 2000 & 67 & 42 & 10 \\
\hline & & Ipra 2000 & & & \\
\hline & & Theo 900 & & & \\
\hline 62 & M & BDP 3000 & 40 & 24 & -19 \\
\hline 55 & $\mathrm{~F}$ & BDP 2000 & 21 & 16 & 6.7 \\
\hline 62 & M & BDP 2000 & 34 & 25 & 1.8 \\
\hline 48 & $\mathrm{~F}$ & BDP 600 & 68 & 60 & 7.6 \\
\hline 32 & $\mathrm{~F}$ & BDP 1000 & 56 & 43 & 1.7 \\
\hline \multirow[t]{2}{*}{69} & M & Bud 1600 & 44 & 35 & 10 \\
\hline & & BDP 2000 & & & \\
\hline 70 & $\mathrm{~F}$ & BDP 2000 & 66 & 17 & 6.7 \\
\hline 68 & $\mathrm{~F}$ & BDP 2000 & 68 & 16 & 1.6 \\
\hline
\end{tabular}

*: therapy (inhaled or oral) at the time of the trial of oral prednisolone (see Methods). All patients were receiving inhaled $\beta_{2}$-agonists. Doses represent total daily doses. \#: change in baseline FEV1 after nebulized salbutamol $5 \mathrm{mg}$ expressed as a percentage of the baseline value; $\$$ : change in baseline FEV1 after trial of oral prednisolone therapy (see Methods) expressed as a percentage of the baseline value. Bud: budesonide; Ipra: ipratropium bromide; Theo: theophylline-based preparation. For further definitions see legend to table 1.

This supplemented medium (hereafter referred to as "medium") was used for all cell culture procedures. Phytohaemagglutinin (PHA-P; Sigma, Poole, UK) was dissolved $\left(100 \mathrm{mg} \cdot \mathrm{mL}^{-1}\right)$ in medium, sterile filtered, stored in aliquots at $-20^{\circ} \mathrm{C}$ and added to cultured cells at a final concentration of $5 \mu \mathrm{g} \cdot \mathrm{mL}^{-1}$. Anti-CD3 murine monoclonal antibody (UCHT-1; a kind gift from D. Cantrell) was dissolved $\left(1 \mathrm{mg} \cdot \mathrm{mL}^{-1}\right)$ in medium, stored at $-80^{\circ} \mathrm{C}$ and added in liquid phase to cultured cells at a final concentration of $500 \mathrm{ng} \cdot \mathrm{mL}^{-1}$. Dexamethasone (Sigma), budesonide (Sigma), beclomethasone dipropionate (Sigma), mycophenolate mofetil (Roche Products Ltd, UK) and FK506 (tacrolimus; Fujisawa Co. Ltd, UK) were dissolved in ethanol, and fluticasone $17 \alpha$-propionate (Glaxo, UK) dissolved in dimethylacetamide to stock concentrations of $10^{-2} \mathrm{~mol} \cdot \mathrm{L}^{-1}$. Cyclosporin A oily suspension (100 $\mathrm{mg} \cdot \mathrm{mL}^{-1}$; Sandoz, Switzerland) was diluted in ethanol, and then in medium to a stock concentration of $10^{-4} \mathrm{~mol} \cdot \mathrm{L}^{-1}$. Aliquots of stock solutions were stored in glass vials at $-20^{\circ} \mathrm{C}$. Serial 10 fold dilutions of drugs were made up at the time of each experiment by dissolving the stock solutions in medium and sterilefiltering through a $0.22 \mu \mathrm{m}$ pore size filter as appropriate. The same stock solutions were used for all experiments.

\section{Peripheral blood mononuclear cell (PBMC) isolation and culture}

Peripheral venous blood $(100 \mathrm{~mL})$ was drawn from each of the patients at time-points remote from the trial of oral GC therapy and $6 \mathrm{~h}$ following a dose of inhaled $\mathrm{GC}$ and was added to preservative-free heparin in a sterile fashion. After mixing with an equal volume of medium, $30 \mathrm{~mL}$ aliquots of diluted blood were layered onto $20 \mathrm{~mL}$ aliquots of Ficoll-Paque (Pharmacia, Uppsala, Sweden) in $50 \mathrm{~mL}$ sterile conical tubes (Falcon; Becton Dickinson, Cowley, UK). After centrifuging $\left(400 \times \mathrm{g}\right.$ for $20 \mathrm{~min}$ at $\left.20^{\circ} \mathrm{C}\right)$, PBMCs were removed from the plasma/Ficoll interface with gentle suction, transferred to sterile polystyrene universal containers, and washed twice with medium.

Effects of drugs on the proliferative response of T-lymphocytes

PBMC were resuspended in medium at $4 \times 10^{6}$ cells $\cdot \mathrm{mL}^{-1}$. Aliquots $(100 \mu \mathrm{L})$ of this cell suspension, with or without added PHA or anti-CD3, were added to $20 \mu \mathrm{L}$ aliquots of serially diluted drug solutions or vehicle control in triplicate in sterile 96-well round-bottomed culture plates (Cel-Cult; Sterilin, Hounslow, UK), and medium was added to produce a final volume of $200 \mu \mathrm{L} \cdot$ well $^{-1}$ and final concentrations of $2 \times 10^{6}$ cells $\cdot \mathrm{mL}^{-1}$, PHA 5 $\mu \mathrm{g} \cdot \mathrm{mL}^{-1}$, anti-CD3 $500 \mathrm{ng} \cdot \mathrm{mL}^{-1}$ and drug solutions as shown in the Results section. Because of the extent of these experiments, the drugs were divided into two groups: dexamethasone, budesonide, beclomethasone dipropionate and fluticasone (first group); and dexamethasone, CsA, FK506 (tacrolimus) and mycophenolate (second group). The effects of each group were measured contemporaneously in separate experiments on 
cells from each subject performed at intervals of up to 4 weeks. Culture plates were incubated $\left(37^{\circ} \mathrm{C}\right.$ for $\left.48 \mathrm{~h}\right)$ in a humidified atmosphere with $5 \%$ carbon dioxide. Cell proliferation was measured by uptake of tritiated thymidine. Sterile tritiated thymidine solution (Amersham, UK) $\left(24.6 \mathrm{kBq} \cdot\right.$ well $^{-1}$ in a volume of $\left.10 \mu \mathrm{L}\right)$ was added to cell culture wells for the last $6-8 \mathrm{~h}$ of the $48 \mathrm{~h}$ incubation period. After incubation, cells were harvested onto glass-fibre filter paper with a cell harvesting apparatus (Skatron, Vier, Norway) and the incorporated radiolabel counted in a $\beta$-spectrometer. After calculating the geometric mean of the triplicate counts, results were expressed as the percentage inhibition of incorporated counts in the presence of drugs as compared with the positive (stimulus with drug vehicle) control. Experiments were considered valid if at least 30,000 counts per minute $(\mathrm{cpm})$ of tritium were incorporated by cells in the positive control wells.

\section{Measurement of steroid metabolism in T-lymphocytes} using the probe substrate progesterone

Aliquots of PBMCs from six of the sensitive and eight of the resistant asthmatics were cultured $\left(48 \mathrm{~h}\right.$ at $\left.37^{\circ} \mathrm{C}\right)$ in medium $\left(2 \times 10^{6}\right.$ cells $\left.\cdot \mathrm{mL}^{-1}\right)$ in the presence of PHA (final concentration $5 \mu \mathrm{g} \cdot \mathrm{mL}^{-1}$ ) in sterile tissue culture flasks (Sterilin). The cells were then resuspended, washed once in medium and the cell pellets stored at $-80^{\circ} \mathrm{C}$ pending analysis. Progesterone, reduced nicotinamide adenine dinucleotide phosphate (NADPH), glucose-6phosphate, glucose-6-phosphate dehydrogenase and magnesium chloride were purchased from Sigma. (1,2,6,7$\left.{ }^{3} \mathrm{H}\right)$ progesterone $\left(37 \mathrm{MBq} \cdot \mathrm{mL}^{-1}, 15 \mathrm{TBq} \cdot \mathrm{mmol}^{-1}\right)$ was purchased from Amersham. All solvents were of high performance liquid chromatography (HPLC) grade and were obtained from Fisons (Loughborough, UK). The PBMC pellets were reconstituted in $5 \mathrm{~mL}$ phosphate buffer $\left(0.1 \mathrm{~mol} \cdot \mathrm{L}^{-1}, \mathrm{pH} 7.4\right)$, agitated vigorously in a vortex mixer for several minutes and then sonicated (three bursts of $30 \mathrm{~s}$ ). The sonicated cell suspension was then mixed with an NADPH regenerating system (NADPH $1 \mathrm{mmol} \cdot \mathrm{L}^{-1}$, glucose-6-phosphate $10 \mathrm{mmol} \cdot \mathrm{L}^{-1}$, glucose6-phosphate dehydrogenase $1 \mathrm{U} \cdot \mathrm{mL}^{-1}$ and magnesium chloride $10 \mathrm{mmol} \cdot \mathrm{L}^{-1}$ ) in phosphate buffer to give a final concentration of $10^{7}$ lysed cells $\cdot \mathrm{mL}^{-1}$. Control incubations were performed in which the NADPH regenerating system was replaced by phosphate buffer $\left(0.1 \mathrm{~mol} \cdot \mathrm{L}^{-1}\right.$, $\mathrm{pH}$ 7.4) alone.

After preincubating $\left(37^{\circ} \mathrm{C}\right.$ for $\left.5 \mathrm{~min}\right)$, the reaction was initiated by addition of tritiated progesterone (50 $\mu \mathrm{mol} \cdot \mathrm{L}^{-1}$ in methanol) to a final concentration of 1 $\mu \mathrm{mol} \cdot \mathrm{L}^{-1}\left(140 \mathrm{kBq} \cdot \mathrm{mL}^{-1}\right)$. The mixture was incubated at $37^{\circ} \mathrm{C}$ for up to $24 \mathrm{~h}$. Aliquots $(500 \mu \mathrm{L})$ of the reaction mixture were removed at various time points $(1$, $2,3,4,5,9$, and $24 \mathrm{~h}$ ) during the incubation, plunged immediately into $4 \mathrm{~mL}$ ice-cold diethylether and agitated vigorously in a vortex mixer for $1 \mathrm{~min}$. The samples were then centrifuged $\left(1000 \times \mathrm{g}\right.$ at $4^{\circ} \mathrm{C}$ for $\left.5 \mathrm{~min}\right)$ and the aqueous phase discarded. After evaporating the remaining diethylether to dryness under a stream of nitrogen, the cellular extract was reconstituted in $1.5 \mathrm{~mL}$ of $50 \%(\mathrm{v} / \mathrm{v})$ methanol.

Analysis of the reconstituted extract was performed by HPLC using ultraviolet $(240 \mathrm{~nm})$ and tritium detection. Aliquots $(500 \mu \mathrm{L})$ of the reconstituted extracts were injected onto a LiChroCART 250-4 C18 column $(7 \mu \mathrm{m}, 250 \times 4 \mathrm{~mm})$ at $50 \%$ mobile phase A:B to $95 \%$ mobile phase $\mathrm{A}: \mathrm{B}$ over $30 \mathrm{~min}$ (A was acetonitrile, B was $0.5 \% \mathrm{w} / \mathrm{v}$ aqueous ammonium acetate). Selected samples were reconstituted with nontritiated progesterone and $20 \alpha$ - and $17 \alpha$-hydroxyprogesterone standards to check for co-chromatography. Quantification of progesterone and its oxidative products was performed by multiplying the initial concentration of progesterone $\left(1000 \mathrm{pmol} \cdot \mathrm{mL}^{-1}\right)$ by the percentage of the total radioactivity detected in the chromatogram associated with the peak of interest, to give progesterone equivalents $\left(\mathrm{pmol} \cdot \mathrm{mL}^{-1}\right)$. These were plotted over time and the rates of progesterone decline and metabolite production (expressed as pmol progesterone equivalents $10^{-7}$ cells $\cdot h^{-1}$ ) calculated from the line of best fit over the first $5 \mathrm{~h}$ of incubation.

\section{Statistical methods}

Statistical differences between pooled data from the GC sensitive and resistant asthmatics were calculated in all cases using the Mann-Whitney U test. Despite the nonparametric analysis, the data are shown graphically as mean \pm SEM for clarity.

\section{Results}

Inhibition of proliferation of T-lymphocytes from GC sensitive and resistant asthmatics by GCs of differing molecular structure

Dexamethasone, beclomethasone dipropionate, budesonide and fluticasone $17 \alpha$-propionate in the concentration range $10^{-11}$ to $10^{-6} \mathrm{~mol} \cdot \mathrm{L}^{-1}$ suppressed proliferation of PHA or anti-CD3 stimulated peripheral blood T-lymphocytes from both GC sensitive and resistant asthma patients in a dose-dependent fashion (figs. 1 and 2). The effects of these drugs were compared for each patient in contemporaneous experiments. Over a wide range of drug concentrations, T-lymphocytes from the patients with GC resistant asthma were less sensitive to inhibition with all four drugs as compared with those from sensitive patients using both the PHA and anti-CD3 stimuli (figs. 1 and 2). No proliferation was observed in the absence of PHA or anti-CD3, whether or not drugs were present (data not shown). Ethanol diluent control experiments showed no effect on T-lymphocyte proliferation at the concentrations used in the lowest drug dilutions (data not shown). Cell viability was maintained ( $>95 \%$ by trypan blue exclusion) throughout the duration of the experiments. Budesonide and fluticasone $17 \alpha$-propionate, but not beclomethasone dipropionate, were more potent than dexamethasone in terms of the median inhibitory concentrations (IC50) of these drugs required to inhibit PHA-induced proliferation of T-lymphocytes from GC sensitive asthmatics (IC50): dexamethasone $6.5 \times$ $10^{-8} \mathrm{~mol} \cdot \mathrm{L}^{-1}$; beclomethasone $1.4 \times 10^{-8} \mathrm{~mol} \cdot \mathrm{L}^{-1}$; budesonide $2.1 \times 10^{-9} \mathrm{~mol} \cdot \mathrm{L}^{-1}(\mathrm{p}<0.002$ vs dexamethasone $)$; fluticasone $3.4 \times 10^{-10} \mathrm{~mol} \cdot \mathrm{L}^{-1}(\mathrm{p}<0.001 \mathrm{vs}$ dexamethasone); (see also fig. 1). This was only evident for fluticasone with the anti-CD3 stimulus (fig. 2). 


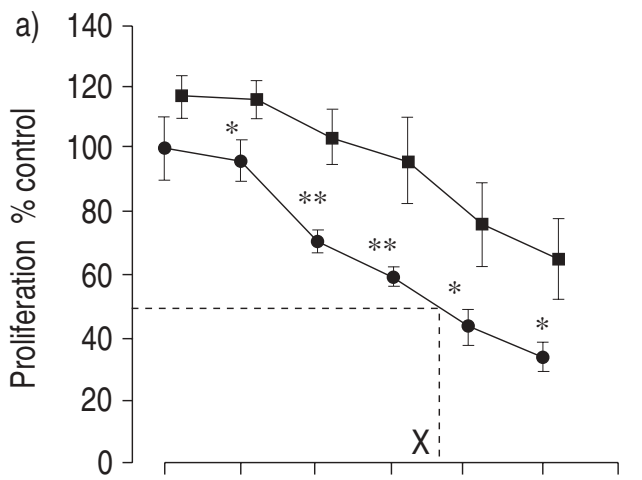

b) 140$] \quad$ [Dexamethasone] $\mathrm{mol} \cdot \mathrm{L}^{-1}$

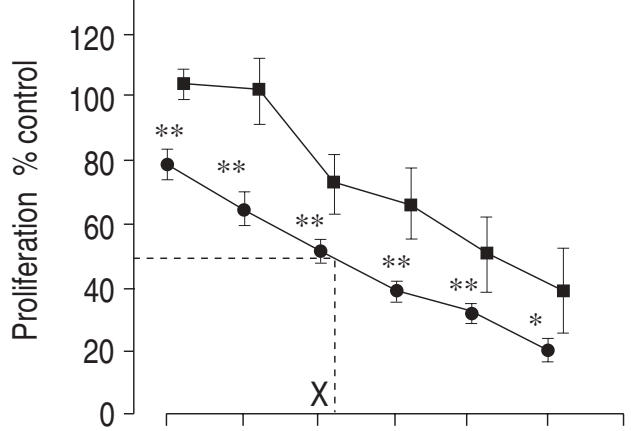

c) 140

[Budesonide] $\mathrm{mol} \cdot \mathrm{L}^{-1}$

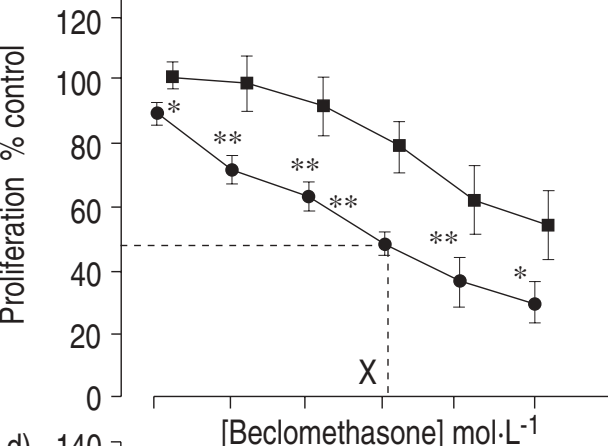

d) 140

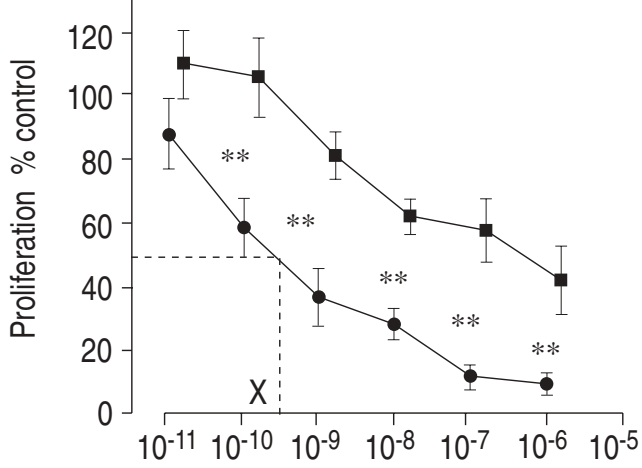

[Fluticasone] $\mathrm{mol}^{-\mathrm{L}^{-1}}$

Fig. 1. - Inhibition of phytohaemagglutinin (PHA)-induced proliferation of peripheral blood T-lymphocytes from glucocorticoid sensitive ( $\square$ ) $; \mathrm{n}=7$ ) and resistant ( $\square ; \mathrm{n}=9$ ) asthmatics by a) dexamethasone, b) budesonide, c) beclomethasone dipropionate and d) fluticasone $17 \alpha$-propionate $\left(10^{-11}\right.$ to $\left.10^{-6} \mathrm{~mol} \cdot \mathrm{L}^{-1}\right)$ in vitro. Points marked $\mathrm{X}$ on the abscissae represent the approximate median inhibitory concentration (IC50) for T-lymphocyte proliferation for each drug in the sensitive patients. Graphs show mean \pm sem proliferation in the presence of drug expressed as a percentage of that observed in the presence of the medium (no drug) control. *: $\mathrm{p}<0.05$; $* *$ : $\mathrm{p}<0.01$ (between group comparisons using Mann-Whitney U-test).
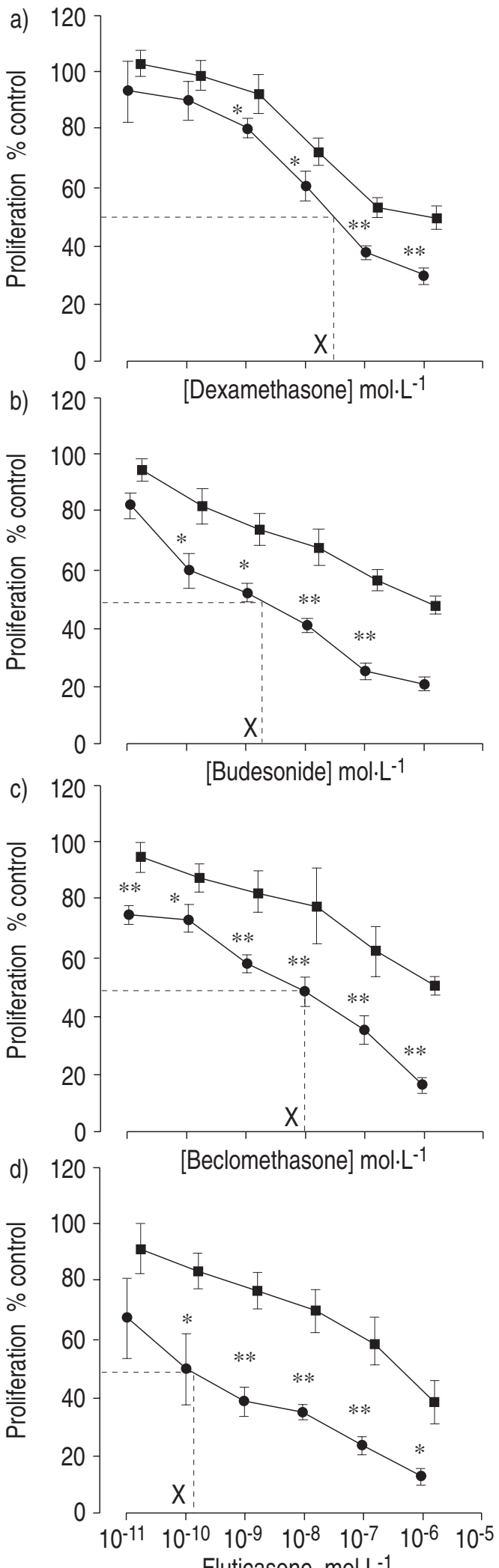

Fluticasone $\mathrm{mol} \cdot \mathrm{L}^{-1}$

Fig. 2. - Inhibition of anti-CD3-induced proliferation of peripheral blood T-lymphocytes from glucocorticoid sensitive (- - n=7) and resistant ( $~ ; n=9)$ asthmatics by a) dexamethasone, b) budesonide, c) beclomethasone dipropionate and d) fluticasone $17 \alpha$ propionate $\left(10^{-11}\right.$ to $\left.10^{-6} \mathrm{~mol} \cdot \mathrm{L}^{-1}\right)$ in vitro. $*$ : $\mathrm{p}<0.05$; $* *: \mathrm{p}<0.01$ (between group comparisons using Mann-Whitney U-test). Points marked $\mathrm{X}$ are explained in the legend to figure 1 . 
a)

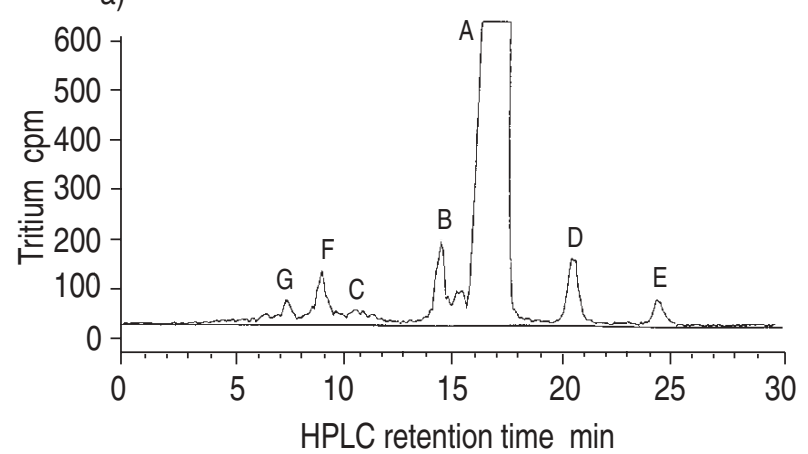

b)

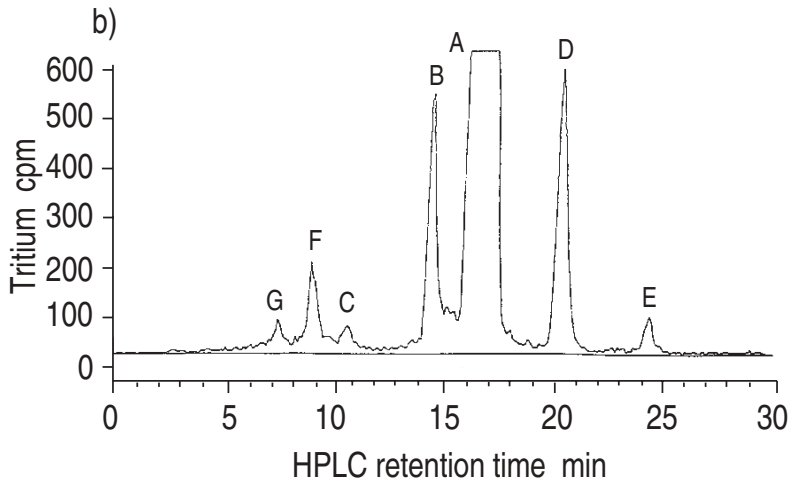

Fig. 3. - High performance liquid chromatography (HPLC) profile of tritiated products following incubation of homogenized T-lymphocytes from a single asthmatic subject in the presence of an NADPH regeneration system with tritiated progesterone for: a) 5h; and b) $24 \mathrm{~h}$ (see Methods). Seven peaks of radioactivity (labelled A-G) are visible, corresponding to distinct progesterone metabolites. In order to show the minor peaks clearly, peak A (corresponding to unmetabolized progesterone, see figure 4) is shown as off-scale. The rate of metabolism of progesterone was calculated for each subject by plotting the rate of decline of the area of peak A over the first $5 \mathrm{~h}$ of incubation when this was linear. NADPH: reduced nicotinamide adenine dinucleotide phosphate; cpm: counts per minute.

Steroid metabolism by T-lymphocytes from GC sensitive and resistant asthmatics

Metabolism of tritiated progesterone by cellular extracts of PHA-stimulated peripheral blood T-lymphocytes from six GC sensitive and eight resistant asthmatics was studied by HPLC as described in the Methods. Figure 3 shows the pattern of chromatographic tritium peaks produced following incubation of the cellular extracts from one typical patient with tritiated progesterone for $5 \mathrm{~h}$ and $24 \mathrm{~h}$. This pattern of peaks was observed in all subjects studied, whether GC sensitive or resistant. The HPLC analysis indicated that there were at least seven progesterone-related chromatographic peaks produced in the incubations containing the NADPH regenerating system, including peaks A, B and $\mathrm{C}$ which co-chromatographed with the progesterone, $20 \alpha$ - and $17 \alpha$-hydroxyprogesterone standards, respectively (figs. 3 and 4), two peaks (D and E) which were less polar than progesterone and two peaks ( $F$ and $G)$ which were more polar than progesterone (fig. 3). Major products B (20 $\alpha$-hydroxyprogesterone) and D were seen in the presence of the NADPH regenerating system but not in control incubations in the absence of co-factors. Peaks C, E, F and G were seen both in the presence

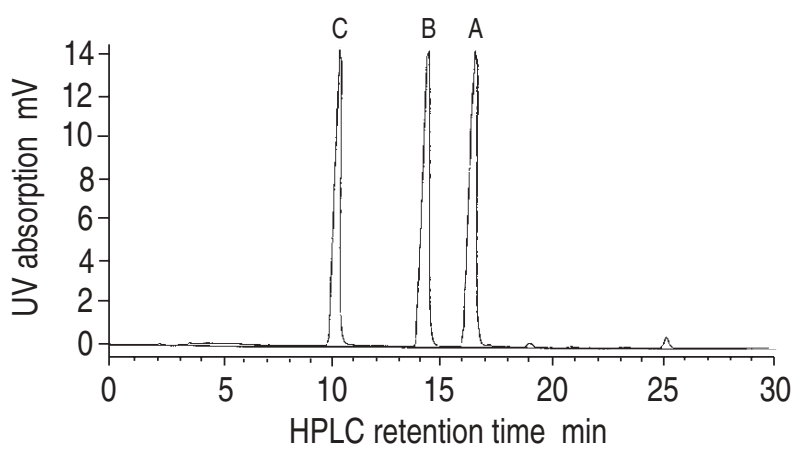

Fig. 4. - High performance liquid chromatography (HPLC) elution profiles of non-radiolabelled standards as detected by ultraviolet (UV) absorption. Peak A $=$ progesterone; peak $\mathrm{B}=20 \alpha$-hydroxyprogesterone; peak $\mathrm{C}=17 \alpha$-hydroxyprogesterone. The retention times of these peaks correspond to those of the peaks A-C in figure 3 (there is a small discrepancy because the UV and tritium detectors are placed in series), thus identifying these products. The remaining peaks (D-G) in figure 3 were not identified. and absence of the NADPH regenerating system. None of these peaks was present in the initial stock of tritiated progesterone.

As measured by comparing the rate of disappearance of tritiated progesterone with the rate of appearance of tritiated $20 \alpha$-hydroxyprogesterone during the first $5 \mathrm{~h}$ of the incubation period when both rates were approximately linear (table 2), 20 $\alpha$-hydroxylation of progesterone accounted for only $14-25 \%$ of the total turnover

Table 2. - Rates of production of $20 \alpha$-hydroxyprogesterone and metabolism of progesterone by PMBC homogenates of six GC sensitive and eight GC resistant asthmatics

\begin{tabular}{|c|c|c|}
\hline & $\begin{array}{l}\text { Rate of production of } \\
\text { hydroxyprogesterone } \\
\text { pmol } \cdot 10^{-7} \text { cells } \cdot \mathrm{h}^{-1 \#}\end{array}$ & $\begin{array}{l}\text { Rate of decline in } \\
\text { progesterone } \\
\text { pmol } \cdot 10^{-7} \text { cells } \cdot \mathrm{h}^{-1 \#}\end{array}$ \\
\hline \multirow[t]{6}{*}{ Sensitive } & 2.0 & 18.1 \\
\hline & 2.1 & 11.5 \\
\hline & 2.0 & 11.4 \\
\hline & 1.67 & 10.6 \\
\hline & 1.32 & 8.6 \\
\hline & 0.78 & 12.0 \\
\hline Mean & $1.65^{\dagger}$ & $12.03^{\dagger}$ \\
\hline SEM & 0.21 & 1.31 \\
\hline \multirow[t]{8}{*}{ Resistant } & 4.9 & 17.9 \\
\hline & 7.1 & 15.9 \\
\hline & 2.8 & 12.6 \\
\hline & 4.2 & 13.3 \\
\hline & 0.79 & 8.4 \\
\hline & 1.31 & 10.0 \\
\hline & 1.85 & 9.5 \\
\hline & 0.66 & 6.0 \\
\hline Mean & $2.95^{\dagger}$ & $11.7^{\dagger}$ \\
\hline SEM & 0.81 & 1.41 \\
\hline
\end{tabular}

\#: homogenates were incubated with tritiated progesterone, and the incubation mixes were sampled at intervals (see Methods). Figures represent standardized rate of appearance of $20 \alpha$-hydroxyprogesterone and decline of progesterone over the first $5 \mathrm{~h}$ of incubation when the curves were approximately linear (see Methods). PBMC: peripheral blood mononuclear cells; GC: glucocorticoid. $\uparrow: \mathrm{p}>0.1$, sensitive $v s$ resistant, (Mann-Whitney U-test). 

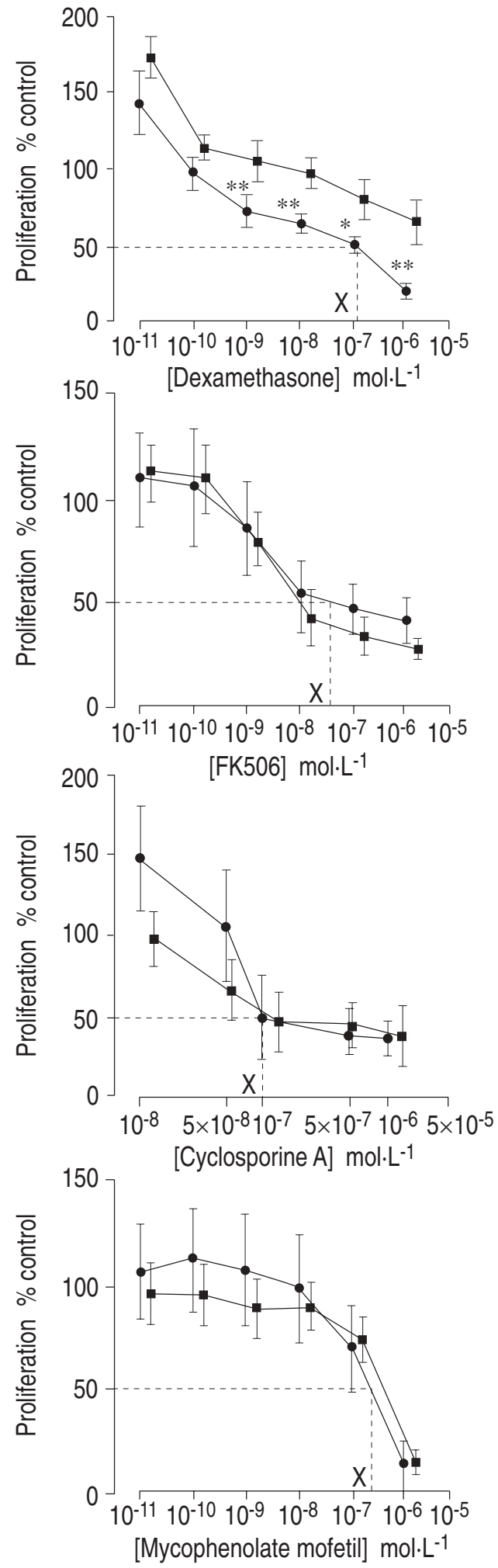

Fig. 5. - Inhibition of phytohaemagglutinin (PHA)-induced proliferation peripheral blood T-lymphocytes from glucocorticoid (GC) sensitive $(\longrightarrow ; n=7)$ and resistant $(-\cdots n=9)$ asthmatics by dexamethasone, cyclosporin A, FK506 (tacrolimus) and mycophenolate mofetil $\left(10^{-11}\right.$ to $10^{-6} \mathrm{~mol} \cdot \mathrm{L}^{-1}$ [cyclosporin A $10^{-8}$ to $10^{-6}$ $\left.\mathrm{mol} \cdot \mathrm{L}^{-1}\right]$ ) in vitro. Points $\mathrm{X}$ on the abscissae represent the approximate proliferation IC50 concentrations for each drug in the sensitive patients. Graphs show mean \pm sem proliferation in the presence of drug expressed as a percentage of that observed in the presence of medium control. IC50: median inhibitory concentration. *: $\mathrm{p}<0.05$; **: $\mathrm{p}<0.01$ (Mann-Whitney U-test).
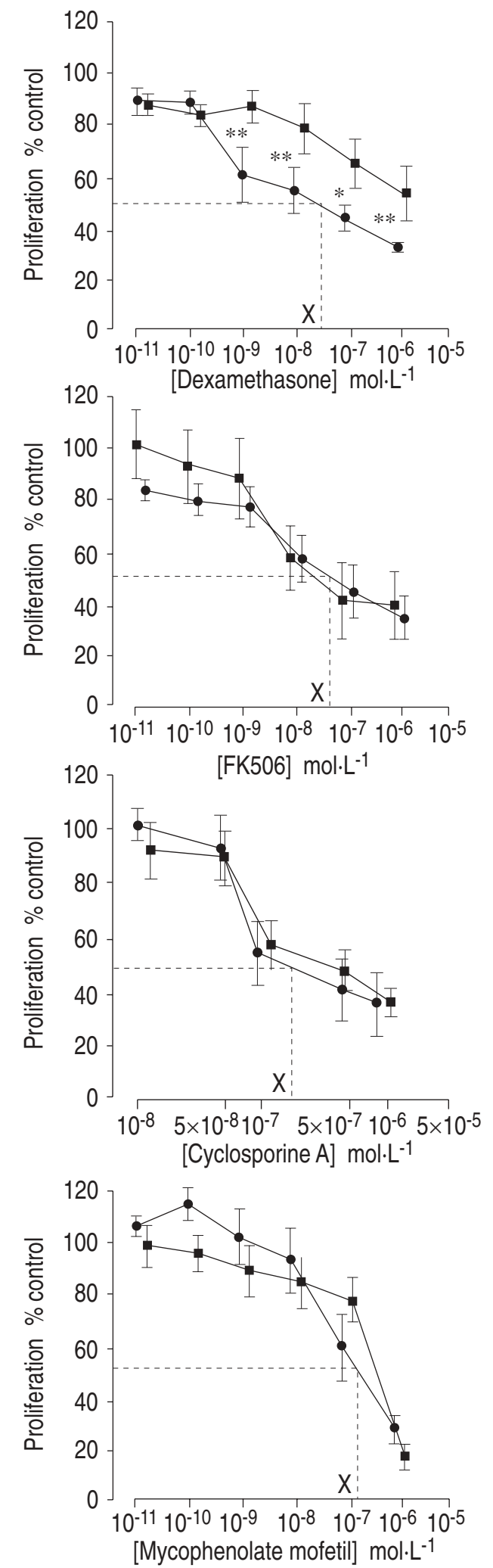

Fig. 6. - Inhibition of anti-CD3-induced proliferation of peripheral blood T-lymphocytes for GC sensitive ( - ; n=7) and resistant (—; n=9) asthmatics by dexamethasone, cyclosporine A, FK506 (tacrolimus) and mycophenolate mofetil $\left(10^{-11}\right.$ to $10^{-6} \mathrm{~mol} \cdot \mathrm{L}^{-1}$ [cyclosporin A $10^{-8}$ to $\left.10^{-6} \mathrm{~mol} \cdot \mathrm{L}^{-1}\right]$ ) in vitro. Graphs show mean \pm SEM proliferation in the presence of drug expressed as a percentage of that observed in the presence of medium control; *: $\mathrm{p}<0.05 ; * *: \mathrm{p}<0.01$ (Mann-Whitney U-test). Points X are explained in the legend to figure 5 . 
in T-lymphocytes both from GC sensitive and resistant asthmatics. The mean rates of $20 \alpha$-hydroxylation and total metabolism of progesterone by T-lymphocytes from the GC sensitive and resistant patients were not significantly different ( $\mathrm{p}>0.1$ in each case) (table 2 ).

Inhibition of proliferation of T-lymphocytes from GC sensitive and resistant asthmatics by the non-GC drugs, cyclosporin A, FK506 (tacrolimus) and mycophenolate mofetil

Dexamethasone, CsA, FK506 (tacrolimus) and mycophenolate mofetil in the concentration range $10^{-11}$ to $10^{-6}$ $\mathrm{mol} \cdot \mathrm{L}^{-1}\left(\mathrm{CsA} 5 \times 10^{-8}\right.$ to $\left.10^{-6} \mathrm{mmol} \cdot \mathrm{L}^{-1}\right)$ suppressed proliferation of PHA or anti-CD3 stimulated peripheral blood T-lymphocytes from patients both with GC sensitive and resistant asthma in a dose-dependent fashion (figs. 5 and 6). The effects of these drugs were compared for each patient in contemporaneous experiments separated by a time interval of $2-4$ weeks from the experiments described in figures 1 and 2 . The differential sensitivity of T-lymphocytes from the GC sensitive and resistant asthmatics to dexamethasone inhibition was maintained. In contrast, CsA, FK506 (tacrolimus) and mycophenolate mofetil inhibited the proliferation of T-lymphocytes induced by both stimuli in both groups of patients with equivalent potency (figs. 5 and 6 ).

\section{Discussion}

In previous studies, we have demonstrated that peripheral blood T-lymphocytes from asthmatic patients clinically resistant to GC therapy are more refractory to the antiproliferative effects of dexamethasone at therapeutically relevant concentrations as compared with cells from GC sensitive asthmatics in vitro $[10,22]$. In this study, we have extended this observation to demonstrate a similar differential sensitivity to GCs commonly used for asthma therapy. We have also addressed the possibility that this difference in GC responsiveness might reflect differing rates of intracellular metabolism of steroids by T-lymphocytes from clinically sensitive and resistant asthmatics.

Firstly, we reasoned that if GC resistance arises from variable intracellular metabolism of these drugs by $\mathrm{T}$ lymphocytes, then GCs with differing molecular structures might be differentially sensitive to this process. The data indicate, however, that peripheral blood Tlymphocytes from GC resistant asthmatics activated both with PHA and anti-CD3 are more refractory, compared with those from sensitive patients, to a variety of GCs in current therapeutic use. This suggests that GC resistance does not depend on the precise structure of the GC molecule itself, and also that asthmatics clinically resistant to prednisolone therapy are also likely be resistant to therapy with other existing antiasthma GCs. It could be argued that it is at least conceivable that therapy of GC resistant asthmatics with topically administered GCs with high ligand binding affinity and prolonged tissue retention, such as fluticasone, might be of some clinical benefit, particularly if these drugs were to attain high concentrations in the bronchial mucosa.
Whilst, it is difficult to entirely refute such an argument, it is noteworthy that this necessitates the presumption that the refractoriness of T-lymphocytes from GC resistant asthmatics to GC inhibition is attributable to a reduced binding affinity of the GC receptor in these cells for its ligand, as has been postulated by some investigators $[15,16]$. These investigators noted a reduced receptor binding affinity $(\mathrm{Kd})$ for dexamethasone binding (approximately $40 \mathrm{nmol} \cdot \mathrm{L}^{-1}$ as compared with 5 $\mathrm{nmol} \cdot \mathrm{L}^{-1}$ in normal controls) in T-lymphocytes from a subset of patients with GC resistant asthma. The present data clearly indicate, however, that the dexamethasone IC50 for proliferation of T-lymphocytes from these patients exceeds $1,000 \mathrm{nmol} \cdot \mathrm{L}^{-1}$ (fig. 1). At this ligand concentration, the GC receptors even in T-lymphocytes from GC resistant asthmatics would be expected to be $>95 \%$ saturated, and yet the refractoriness to GC inhibition is still apparent. For this reason, we believe that this phenomenon is of questionable physiological significance, and that the presence of ligands with higher GC receptor binding affinity, even at high concentrations, could further increase receptor saturation by only a small degree. Similarly, it is not clear whether or not the previously reported reduced DNA binding of the GC receptor/ligand complex in T-lymphocytes from GC resistant patients [18] would be enhanced in the presence of ligands of higher binding affinity.

Secondly, steroid metabolism was measured in peripheral blood T-lymphocytes from GC sensitive and resistant asthmatics. Progesterone was chosen, rather than a GC for this purpose since this steroid is a well-established marker for $20 \alpha-H S D H$ activity and we wished to compare the data obtained with previous studies in the literature suggesting that $20 \alpha$-hydroxylation is a major metabolic pathway for steroid inactivation both in murine and human T-lymphocytes [19, 20, 23]. Furthermore, previous studies have suggested that $20 \alpha-H S D H$ activity was higher in T-lymphocytes relatively resistant to GC inhibition $[19,20]$. The present data (table 2) indicate, however, that $20 \alpha$-hydroxyprogesterone was not the predominant initial metabolite, accounting for only $14-25 \%$ of the total progesterone turnover, and implying that $20 \alpha$-hydroxylation is not rate-limiting for steroid deactivation in human T-lymphocytes. It would appear that this pathway of steroid metabolism is one of several in T-lymphocytes from asthmatic patients.

The HPLC analyses (figs. 3 and 4) indicated that there were at least seven progesterone-related chromatographic peaks produced in the incubations containing the NADPH regenerating system, three of which were characterized by co-chromatrography with standards. Metabolism of progesterone by other animal and human tissues has been reported to result in the production of metabolites hydroxylated at the $16 \alpha, 17 \alpha, 20 \alpha$ and $21 \alpha$ positions, androstenedione, $5 \alpha$-dihydroprogesterone and $3 \alpha$, $5 \alpha$-tetrahydroprogesterone [24-28]. It is possible that some of the chromatographic peaks observed correspond to these metabolites. Further, more detailed investigations would be required to identify all the chromatographic peaks generated from these T-lymphocytes. In view of the multiple metabolites produced, and our evidence that steroid $20 \alpha$-hydroxylation was not rate-limiting, it was considered more appropriate to compare the 
overall rates of metabolism of progesterone itself in the T-lymphocytes from the GC sensitive and resistant asthmatic patients (table 2). This comparison indicated that there was no significant difference between the two patient groups, implying that GC resistance cannot be attributed to increased steroid metabolism within the T-lymphocyte. Finally, it should be noted that these experiments were performed on homogenates of PBMC rather than T-lymphocytes. Although T-lymphocytes comprise the majority of cells in PBMC (typically 80$90 \%$ ), they may contain up to $10 \%$ monocytes and a small minority (typically $<5 \%$ ) of B-lymphocytes. We consider it unlikely, therefore, that the total progesterone metabolism by PBMC could have been influenced predominantly by non-T-lymphocytes, although it is certainly possible that some of the observed metabolites may have arisen from cells other than T-lymphocytes.

Thirdly, we wished to compare the effects of other immunosuppressive drugs for their inhibitory effects on T-lymphocytes from GC sensitive and resistant asthmatics. We reasoned that drugs which inhibit T-lymphocytes by mechanisms distinct from those of GC might inhibit T-lymphocytes from GC refractory asthmatics in vitro. CsA and FK506 (tacrolimus) bind to intracellular proteins termed immunophilins The drug/immunophilin complexes then bind to and inhibit calcineurin, a serine/threonine phosphatase which dephosphorylates the cytoplasmic subunit of the IL-2 transcriptional regulator nuclear factor of activated T-cells (NF-AT), allowing it to migrate into the cell nucleus [28-30]. Mycophenolate mofetil is de-esterified to mycophenolic acid by human cells. This is a potent and specific inhibitor of the enzyme, inosine monophosphate dehydrogenase, which is required by T-lymphocytes and B-lymphocytes for the de dovo synthesis of guanosine nucleotides. It is, thus, a selective suppressor both of T- and B-lymphocyte proliferation [31]. All of these drugs have been used clinically for immunosuppression, principally for prevention of rejection of allografts.

As shown in figures 5 and 6, CsA, FK506 (tacrolimus) and mycophenolate mofetil inhibited PHA- or antiCD3-induced proliferation of T-lymphocytes from GC sensitive and resistant asthmatics with equivalent potency and at IC50 concentrations considerably less than those for all of the GCs tested in the GC resistant asthmatics. This supports our hypothesis that the observed cellular defect in T-lymphocytes from resistant asthmatics is confined to GC-mediated inhibitory mechanisms. The data relating to CsA confirm our previous reports $[21,22]$. The experiments described in figures 1 and 2, and 5 and 6 , which were performed on the same subjects at different times, confirm the repeatability of the measurements within individual patients in the short term, as demonstrated previously [23]. We have also shown previously [22] that the range of concentrations of the drugs employed in this study encompasses the therapeutic range, although the optimal therapeutic concentration of mycophenolate mofetil has yet to be established. Although it is not possible to compare the local concentrations of these drugs achieved in the asthmatic bronchial mucosa by oral therapy (or topical therapy in the case of GCs), these data are at least compatible with the hypothesis that these immunosuppressive agents may be useful at therapeutic concentrations for the therapy of GC resistant asthmatics, whose T-lymphocytes are not inhibited by currently available GCs at dosages considered therapeutically acceptable.

In summary, we have further investigated the mechanism whereby T-lymphocytes from GC resistant asthmatics are resistant to the inhibitory effects of GCs in vitro. We have shown that this phenomenon is unlikely to be dependent on variable intracellular metabolism of GCs by T-lymphocytes, since: 1) it is observed with GCs of differing structures; and 2) there is no evidence of enhanced steroid metabolism in resistant cells. Our data suggest that T-lymphocytes from GC resistant asthmatics are less likely to be inhibited by therapeutic concentrations [10, 22] of GCs currently employed for asthma therapy and, furthermore, that other anti-T-lymphocyte drugs, used alone or in combination, may be effective for the therapy of GC resistant asthma. We recently showed in two double-blind trials that CsA therapy improved lung function and reduced the frequency of disease exacerbations [32], and allowed significant reduction of oral GC therapy while improving lung function [33], in groups of patients with chronic, severe, GC-dependent asthma, although this has not been confirmed in a third study [34]. These data suggest that the antiproliferative effects of CsA on T-lymphocytes from asthmatics may be a poor predictor of clinical efficacy (which is not to say that CsA is clinically ineffective). Further studies may clarify whether or not potentially more relevant in vitro assays (such as inhibition of secretion of asthma-relevant cytokines) may better predict clinical response. Whatever the case, the current findings suggest that clinical studies to assess drugs, such as FK506 (tacrolimus) and mycophenolate mofetil, for their efficacy and safety in the therapy of asthma would be justified, especially in those patients with glucocorticoid refractory disease.

\section{References}

1. Azzawi M, Bradley B, Jeffery PK, et al. Identification of activated T-lymphocytes and eosinophils in bronchial biopsies in stable atopic asthma. Am Rev Respir Dis 1990; 142: 1407-1413.

2. Corrigan CJ, Hartnell A, Kay AB. T-lymphocyte activation in acute severe asthma. Lancet 1988; i: 11291132.

3. Walker C, Kaegi MK, Braun P, Blaser K. Activated Tcells and eosinophilia in bronchoalveolar lavages from subjects with asthma correlated with disease severity. $J$ Allergy Clin Immunol 1991; 88: 935-942.

4. Lassalle P, Sergant M, Delneste Y, et al. Levels of soluble IL-2 receptor in plasma from asthmatics: correlations with blood eosinophilia, lung function and glucocorticoid therapy. Clin Exp Immunol 1992; 87: 266-271.

5. Corrigan CJ, Kay AB. CD4 T-lymphocyte activation in acute severe asthma: relationship to disease severity and atopic status. Am Rev Respir Dis 1990; 141: 970-977.

6. Hamid Q, Azzawi M, Ying S, et al. Interleukin-5 mRNA in mucosal bronchial biopsies from asthmatic subjects. J Clin Invest 1991; 87: 1541-1546.

7. Robinson DS, Hamid Q, Ying S, et al. Predominant Th2-like bronchoalveolar T-lymphocyte population in atopic asthma. N Engl J Med 1992; 326: 298-304.

8. Robinson DS, Hamid Q, Ying S, et al. Prednisolone 
treatment in asthma is associated with modulation of bronchoalveolar lavage cell interleukin-4, interleukin-5 and interferon-gamma cytokine gene expression. Am Rev Respir Dis 1993; 148: 402-406.

9. Carmichael J, Paterson IC, Diaz P, Crompton GK, Kay $\mathrm{AB}$, Grant IBW. Corticosteroid resistance in chronic asthma. Br Med J 1981; 282: 1419-1422.

10. Corrigan CJ, Brown PH, Barnes NC, et al. Glucocorticoid resistance in chronic asthma: glucocorticoid pharmacokinetics, glucocorticoid receptor characteristics, and inhibition of peripheral blood T-cell proliferation by glucocorticoids in vitro. Am Rev Respir Dis 1991; 144: 1016-1025.

11. Lane SJ, Palmer JBD, Skidmore IF, Lee TH. Corticosteroid pharmokinetics in asthma. Lancet 1990; 336: 1265.

12. Poznansky MC, Gordon ACH, Douglas JG, Krajewski AS, Wyllie AH, Grant IWB. Resistance to methylprednisolone in cultures of blood mononuclear cells from corticosteroid-resistant asthmatic patients. Clin Sci 1984; 67: 639-645.

13. Leung DYM, Martin RJ, Szefier SJ, et al. Dysregulation of interleukin-4, interleukin-5 and interferon-gamma gene expression in steroid-resistant asthma. J Exp Med 1995; 181: 33-40.

14. Beato M. Gene regulation by steroid hormones. Cell 1989; 56: 335-344

15. Sher ER, Leung DYM, Surs W, et al. Steroid-resistant asthma: cellular mechanisms contributing to inadequate responses to glucocorticoid therapy. J Clin Invest 1994; 93: 33-39.

16. Kam JC, Szefler SJ, Surs W, Sher ER, Leung DYM. Combination IL-2 and IL-4 reduces glucocorticoid receptor-binding affinity and T-cell response to glucocorticoids. J Immunol 1993; 151: 3460-3466.

17. Lane SJ, Arm JP, Staynov DZ, Lee TH. Chemical mutational analysis of the human glucocorticoid receptor mRNA in glucocorticoid resistant bronchial asthma. Am J Respir Cell Mol Biol 1994; 11: 42-48.

18. Adcock IM, Lane SJ, Brown CR, Peters MJ, Lee TH, Barnes PJ. Differences in binding of glucocorticoid receptor to DNA in steroid-resistant asthma. J Immunol 1995; 154: 3500-3505.

19. Hapel A, Osborne J, Fung M, Young I, Allan W, Hume D. Expression of $20 \alpha$-hydroxysteroid dehydrogenase in mouse macrophages, hemopoietic cells and cell lines and its induction by colony-stimulating factors. J Immunol 1985; 134: 2492-2497.

20. Weinstein Y. 20 $\alpha$-hydroxysteroid dehydrogenase: a Tlymphocyte associated enzyme. J Immunol 1977; 119: 1223-1229.

21. Corrigan CJ, Brown PH, Barnes NC, Tsai JJ, Frew AJ, Kay AB. Glucocorticoid resistance in chronic asthma: peripheral blood T-lymphocyte activation and a comparison of the T-lymphocyte inhibitory effects of glucocorticoids and cyclosporin A. Am Rev Respir Dis 1991; 144: 1026-1032.

22. Haczku A, Alexander A, Brown P, et al. The effect of dexamethasone, cyclosporin, and rapamycin on T-lymphocyte proliferation in vitro: comparison of cells from patients with glucocoriticoid-sensitive and glucocorticoid-resistant chronic asthma. J Allergy Clin Immunol 1994; 93: 510-519.

23. Carbone A, Piantelli P, Musani L, Larocca R. Expression of $20 \alpha$-hydroxysteroid dehydrogenase activity in human lymphoid and nonlymphoid cells. Clin Exp Immunol 1986; 63: 203-209.

24. Ding X, Coon M. Steroid metabolism by rabbit olfactory specific P450 2G1. Arch Biochem Biophys 1994; 315: 454-459.

25. Kitareewan S, Walz F. Genetic and developmental diversity of hepatic cytochrome P450. Drug Metab Disp 1994; 22: 607-615.

26. Korneyev A, Guidotti A, Costa E. Regional and interspecies differences in brain progesterone metabolism. $J$ Neurochem 1993; 61: 2041-2047.

27. Swart P, Swart A, Waterman M, Estabrook R, Mason J. Progesterone $16 \alpha$-hydroxylase activity is catalyzed by human cytochrome P450 $17 \alpha$-hydroxylase. J Clin Endocrin Metab 1993; 77: 98-102.

28. Granelli-Piperno A, Nolan P, Inaba K, Steinman RM. The effect of immunosuppressive agents on the induction of nuclear factors that bind to sites on the interleukin-2 promoter. J Exp Med 1990; 172: 1869-1872.

29. Wu J, Palladino MA, Figari I, Morris RE. Comparative immunoregulatory effects of rapamycin, FK-506 and cyclosporin on mitogen-induced cytokine production and lymphoproliferation. Transplant Proc 1991; 23: 238-240.

30. Metcalfe SM, Richards FM. Cyclosporin, FK-506 and rapamycin. Transplantation 1990; 49: 798-802.

31. European Mycophenolate Mofetil Co-operative Study Group. Placebo-controlled study of mycophenolate mofetil combined with cyclosporin and corticosteroids for prevention of acute rejection. Lancet 1995; 345: 1321-1325.

32. Alexander AG, Barnes NC, Kay AB. Trial of cyclosporin A in corticosteroid-dependent chronic severe asthma. Lancet 1992; 339: 324-328.

33. Lock SH, Kay AB, Barnes NC. Double-blind, placebocontrolled study of cyclosporin A as a corticosteroidsparing agent in corticosteroid-dependent asthma. Am J Respir Crit Care Med 1996; 153: 509-514.

34. Nizankowska E, Soja J, Pinis G, et al. Treatment of steroid-dependent bronchial asthma with cyclosporin. Eur Respir J 1995; 8: 1091-1099. 